Journal of Research in Interprofessional

Practice and

Education

Vol. 5.1

March 2015
Journal of Research in Interprofessional Practice and Education (JRIPE)

Vol. 5.1

(C) 2015

Corresponding author: Meredith McKague. Email: m.mckague@usask.ca

\section{Deeper Learning through Service: Evaluation of an Interprofessional Community Service-Learning Program for Pharmacy and Medicine Students}

\author{
Megan Clark, MD; Meredith McKague, MD, MSc, CCFP; \\ Shari McKay, MA; \& Vivian R Ramsden, RN, PhD
}

\begin{abstract}
Background: This community service-learning project (CSLP) at the University of Saskatchewan is designed to help students develop patient-centred care practices in urban underserved settings. First-year medical and pharmacy students partner interprofessionally to both learn and serve, working with community-based organizations (CBOs) that primarily serve either low-income or newcomer residents of Saskatoon. From the CSLP's pilot year in 2005-2006 to the end of the 2013-2014 year, 105 first-year medical and pharmacy students have participated in the CSLP.

Methods and Findings: We evaluated the student learning processes and outcomes of the CSLP from its inception in the 2006-2007 academic year until 2010-2011 using end-of-project questionnaires; document analysis looking for key and recurrent themes; and semi-structured interviews with $\mathrm{CBO}$ clients and coordinators. Of interest were students' experiences, including satisfaction, achievement of learning objectives, learning processes, and perceived outcomes. Students' main learning outcomes related to client-centred approaches, interprofessional attitudes and skills, and personal development. These triangulated with what $\mathrm{CBO}$ coordinators and clients reported. Various learnings related to program processes were reported.

Conclusions: Students described a transformative learning experience that helped them begin to develop understanding and skills to work more effectively with clients in urban underserved settings.
\end{abstract}

Keywords: Service-learning; Interprofessional education; Mixed methods; Underserved populations; Program evaluation

\section{Introduction}

Internationally and within Canada, social accountability has been identified as a key priority for medical schools [1-3]. This article describes an initiative to foster and support social accountability through an interprofessional community service-learning program for pharmacy and medical students.

\section{Service-learning}

Service-learning, a "type of experiential education in which students learn through 
2

IP CSLP Evaluation

Clark, McKague, McKay, \& Ramsden

Journal of Research in Interprofessional Practice and Education

Vol. 5.1

March 2015 serving others" [4], is a method that supports social accountability. Service-learning is distinct from both clinical placements and basic volunteering in that it puts equal emphasis on service and learning, focusing on reciprocal benefits to students and the community $[5,6]$. Through reflection, students both apply their academic coursework and explore their roles as responsible members of society, "[bridging] the classroom and the community" [5]. Reflection has been shown to effectively link service and learning. A study on service-learning for pharmacy students found that:

The depth and breadth of what the students learned may not be effectively captured in a series of attitudinal statements, but by their reflection exercises. Although the students may not fully realize the value of their written assignments, it is an effective way to ensure that the links between service and learning are established. [4]

The World Health Organization identifies synergetic, reciprocal relationships between communities and academic institutions as crucial to achieving social accountability [7]. Community-based settings allow students to learn about concepts relevant to becoming socially accountable professionals including: continuity of care; health promotion and disease prevention; communication skills; social, financial and ethical aspects of care; and health issues of underserved communities [6].

Health Canada states that creating socially accountable healthcare providers includes "ensuring that students ... understand the contributions of other healthcare disciplines and have the ability to practice within an interdisciplinary team" [8]. The Centre for the Advancement of Interprofessional Education defines interprofessional education as "when two or more professions learn with, from and about each other to improve collaboration and the quality of care" [9]. Service-learning aims to recognize and respond to societal needs, and interprofessional education aims to form teams to meet those needs.

Key teaching and learning methods underpin service-learning and interprofessional education. Service-learning requires adequate support by means of clear service and learning goals as well as training, supervision, monitoring, support, recognition, and evaluation [5]. Faculty who are part of service and interprofessional learning take on the unconventional role of facilitator, coach, or team leader as opposed to content expert [10], as both service-learning and interprofessional education focus on collaboration among equal members of a team.

Outcomes of interprofessional education and service-learning show promise in creating a more socially accountable, patient-centred healthcare system. A review that examined 107 "higher quality" published evaluations of interprofessional education found that interprofessional education meets its goals of creating positive interaction between different health professions, encouraging collaboration between professions, and improving client care [11]. Service-learning has been found to improve communication skills $[4,12]$; understanding of health needs [4] and community social needs [4,6,12]; "understanding of human diversity and commonality" [10]; ethical and spiritual development and advocacy [10]; leadership skills [12]; volunteerism [6,12,13]; interest in community-based practice [10]; and a change in attitudes [6]. Other stud- 
IP CSLP Evaluation

Clark, McKague, McKay, \& Ramsden

ies did not find change in attitudes towards underserved groups, but attributed this to a ceiling effect from students entering the service-learning project already having altruistic and open-minded attitudes [4,14]. Service-learning, especially interprofessional service-learning, appears to be an effective way for students to learn how to better provide patient-centred care and uphold societal responsibilities.

\section{Methods}

\section{Setting}

The community service-learning program (CSLP) at the University of Saskatchewan in western Canada is a joint venture between the Colleges of Pharmacy/Nutrition and Medicine. Its aim is to help students develop patient-client-centred ${ }^{1}$ knowledge, skills and attitudes in urban underserved settings. First-year medical and pharmacy students partner with community-based organizations (CBOs) in Saskatoon, Saskatchewan, that primarily work with low-income or newcomer residents. Participating CBOs have included a transitional home for young mothers, a local food security agency, an outreach mission, a student-run clinic offering programming and clinical services, a support organization for newcomers to Canada, a youth mentoring organization, and an alternative high school. All students since the 2006-2007 year have had direct client contact through CBOs.

For medical students, the CSLP is an alternative to a rural clinical placement, and for pharmacy students it is an interprofessional alternative in a mandatory servicelearning program. From the CSLP's pilot year in 2005-2006 until the end of 2013-2014, 105 first-year students (50 from medicine and 55 from pharmacy) have partnered to complete the program, which included the following components: a group orientation session; two group reflective sessions; a CBO-specific orientation; a minimum of 60 hours of community service over six to seven months; journaling throughout the project; and a reflective final assignment.

Various evaluations of the program have been undertaken, including a process evaluation exploring student and $\mathrm{CBO}$ coordinator experiences during the program pilot year 2005-2006, and an evaluation of CBO client and supervisor experiences with the program in 2010-2011. In this article, we report on students' experiences from the 2006-2007 to 2010-2011 academic years and CBO supervisors' and clients' experiences in 2010-2011.

\section{Research/evaluation questions}

- What were the experiences of students in the CSLP with respect to:

$\square$ achievement of the CSLP's stated student learning objectives

Journal of Research in Interprofessional Practice and Education

Vol. 5.1

March 2015
- knowledge and attitudes related to interprofessional roles,

- understanding of the health needs and resources of the individuals, families, and communities who access $\mathrm{CBO}$ services,

- knowledge levels of the services of specific CBOs 
IP CSLP Evaluation

Clark, McKague, McKay, \& Ramsden
Journal of Research in Interprofessional Practice and Education

Vol. 5.1

March 2015
Journal of Research in Interprofessional Practice and Education

$\square$ satisfaction with the CSLP's processes and suggestions for potential improvements, and

$\square$ learning processes?

- What were the experiences of participating CBO supervisors, including their:

$\square$ observations of the CSLP's outcomes for students,

$\square$ observations of the CSLP's outcomes for their clients, organization, and themselves, and

$\square$ satisfaction with the processes of the CSLP, and suggestions for potential improvements?

- What were the experiences of CBO clients working with CSLP students, including their:

$\square$ observations of the CSLP's outcomes for students,

$\square$ observations of the CSLP's outcomes for themselves, and

$\square$ satisfaction of the processes of the CSLP, and suggestions for potential improvements?

\section{Design}

This mixed methods study combined a convergent parallel design with a transformative design, both as described by Creswell [15]. The majority of the quantitative and qualitative data (from questionnaires and documents) were collected and analyzed simultaneously, and then additional qualitative data collection and analysis (in the form of interviews) followed. Mixed methods were chosen in order to triangulate findings and enhance our ability to answer the research questions. Sources of data included:

1. Student end-of-project questionnaires which assessed the perceived effectiveness of CSLP processes and students' perceived changes in knowledge, attitudes and skills as related to the program objectives.

All questionnaire items allowed students to give written comments. Most items had students rate their agreement with statements using a five-point Likert scale ( $1=$ strongly disagree to $5=$ strongly agree); one item had students rank, in order, the top three health/social issues they perceived to affect clients at their CBO placement, and another item had them rate their collaboration with their medicine/pharmacy partner on a five-point scale.

The end-of-project questionnaire was designed by the program coordinators and piloted with a group of nine students during the program's pilot year (2005-2006). Revisions were made to the questionnaire based on the initial feedback from students and $\mathrm{CBO}$ supervisors and it was subsequently used in the following years.

2. Student documents, including:

a) orientation reflective exercises (completed individually), 
IP CSLP Evaluation

Clark, McKague, McKay, \& Ramsden b) mid-point reflective exercises (completed by each pair of CSLP partners),

c) final group reflective exercises (completed by each pair of CSLP partners) and

d) the final reflective assignment (completed individually).

Reflective exercises (a through c) included questions for guided reflection on student expectations of the program, as well as reflections of interprofessional practice and on community resources and health needs of the clients they worked with. For the reflective assignment (d), students were asked to write a maximum of 250 words reflecting on their experiences and learnings.

3. $\mathrm{CBO}$ coordinator/client end-of-project semi-structured interviews.

\section{Sampling and data gathering}

All 58 CSLP participants (29 first-year medical students and 29 first-year pharmacy students) that had participated in the CSLP from 2006-2007 to 2010-2011 were invited to participate in the program evaluation.

\section{Students}

Completion of the end-of-project questionnaires was optional for students; questionnaires were distributed to all students at the final reflective session and students were provided with envelopes to return these anonymously. Students received an email reminder to return questionnaires approximately two weeks after initial distribution. While all students were required to complete group reflective exercises and individual reflective assignments, this data was available to the researchers only with consent from the participants; thus, all students (except 2009-2010 students) were provided with an informed consent and invited to have their documents included in this aspect of the study. If they agreed to participate by giving consent, these documents were anonymized, made available to the researchers and included in the document analysis.

\section{CBO coordinators}

All three CBO coordinators from the previous year's (2010-2011) three participating $\mathrm{CBOs}$ were invited to participate by the researchers, and agreed to be interviewed.

\section{CBO clients}

A purposeful sampling strategy was used. $\mathrm{CBO}$ coordinators were invited to suggest potential clients who might be willing to participate in interviews as informationrich informants. The initial contact with the potential client interviewees was by the $\mathrm{CBO}$ coordinators, as they felt that their existing relationship with clients might make clients more comfortable with that contact. After initial contact by the CBO coordinators, interested clients were contacted by researchers.

For both $\mathrm{CBO}$ and client interviews, we obtained written informed consent and the semi-structured interview was conducted by the primary researcher at either 
JRIPE

6

IP CSLP Evaluation

Clark, McKague, McKay, \& Ramsden
CBOs or clients' homes. The primary researcher then transcribed the interviews verbatim.

This evaluation project was approved by the University of Saskatchewan's College of Medicine Research Ethics Committee.

\section{Analysis}

The quantitative data from the end-of project questionnaire were entered into SPSS v. 19 for analysis.

The qualitative data from student comments on the end-of-project questionnaire and student documents were analyzed using inductive, thematic analysis. The primary researcher (MC) read and re-read documents and then assigned initial descriptive codes manually. Initial codes were reviewed and compared and sections of data were organized into themes. A second researcher (MM) independently reviewed a selection of documents and coded and categorized data and identified emerging themes, using the same approach. The researchers then reviewed and re-analyzed results together to further refine descriptions of emerging themes. When different interpretations of data were identified by the two researchers, they reviewed data from other documents to compare or contrast meanings, and collaboratively revised their understanding and description of the emerging category or theme.

Data from the reflective exercises and assignments were compared to student comments on the questionnaire as one mechanism for triangulating data using different data sources. Triangulation also occurred through the use of multiple student participants as informants, and through the comparison of data from students with data from $\mathrm{CBO}$ coordinators and clients [16].

\section{Results}

Of the 58 CSLP participants from 2006-2007 to 2010-2011 (Table 1), 32 questionnaires were returned, for a participation rate of $55 \%(32 / 58)$. Of the 32 who returned

Table 1.

\section{Participation by year. Table lists number of total CSLP participants by year, then specifies how many each year participated in our study.}

\begin{tabular}{|l|l|l|l|}
\hline Year & $\begin{array}{l}\text { Total \# of CSLP } \\
\text { participants }\end{array}$ & $\begin{array}{l}\text { \# of questionnaires } \\
\text { returned }\end{array}$ & $\begin{array}{l}\text { \# of CSLP participants who } \\
\text { consented to document review }\end{array}$ \\
\hline $\mathbf{2 0 0 6}-\mathbf{2 0 0 7}$ & 6 & 5 & 5 \\
\hline $\mathbf{2 0 0 7 - 2 0 0 8}$ & 16 & 9 & 8 \\
\hline $\mathbf{2 0 0 8 - 2 0 0 9}$ & 10 & 4 & 4 \\
\hline $\mathbf{2 0 0 9 - 2 0 1 0}$ & 9 & 6 & 0 (Consent not sought) \\
\hline $\mathbf{2 0 1 0 - 2 0 1 1}$ & 17 & 8 & 7 \\
\hline Total & $\mathbf{5 8}$ & $\mathbf{3 2}$ & $\mathbf{2 4}$ \\
\hline
\end{tabular}

Journal of Research in Interprofessional Practice and Education

Vol. 5.1

March 2015 
IP CSLP Evaluation

Clark, McKague, McKay, \& Ramsden

Journal of Research in Interprofessional Practice and Education

Vol. 5.1

March 2015
Journal of Research in Interprofessional Practice and Education

the questionnaires, 24 consented to have their documents reviewed. Of the participants, $72 \%$ (42/58) self-identified as female and 28\% (16/58) as male.

\section{Student outcomes: Questionnaire and document analysis}

\section{Achievement of learning objectives}

\section{INTERPROFESSIONAL EDUCATION}

Students' main reported interprofessional learnings were in the areas of attitudes toward interprofessionalism and teamwork skills. Many students entered the program already reporting an interest in interprofessionalism. Students very seldom acted in roles specific to medicine/pharmacy at their CBO placements, and students were generally comfortable with this because as junior students, they felt they lacked discipline-specific knowledge. Despite not having discipline-specific roles, students reported seeing the benefits of interprofessionalism:

The other thing I've learned to appreciate at [CBO placement] is that interdisciplinary care is the most comprehensive, holistic, and rewarding way to "do" health care (and community work). So much is gained by communicating and cooperating with others who bring different strengths and points of view from their respective backgrounds. It's really beneficial for patients to have a team working with them ...

Many students expressed interest in future interprofessional practice based on their CSLP experience $(M=4.5, S D=0.57)$. Ninety-seven percent $(N=30)$ either agreed or strongly agreed that they would consider taking part in future interprofessional activities.

Students' skills for interprofessional teamwork increased in that many reported that their communication and relationship-building skills improved. However, understanding of how an interprofessional team works together, and of contributions of other healthcare professionals and non-healthcare professionals, increased for some but not others. We found this despite the fact that students observed many different professionals (including nurses, social workers, addictions outreach workers, physical therapists, occupational therapists, ministry outreach workers, nurse practitioners, cultural support workers, teachers, school staff, and dieticians), and even though some students reported learning about other professionals by volunteering alongside other $\mathrm{CBO}$ volunteers (besides their CSLP partner) who were students in those professions. Only $62.5 \%$ of students $(N=32)$ agreed or strongly agreed that they had increased understanding of the contributions of members of other healthcare professions.

Building teamwork skills for interprofessional practice was the most prominent outcome of the partnerships. One student stated:

Being that we were both first years in our respective colleges, we did not have an extensive background in our areas to draw on at first, but 
IP CSLP Evaluation

Clark, McKague, McKay, \& Ramsden this program, I found, was more about working together as individuals more than medical or pharmacy students.

Some partnerships also discussed discipline-specific topics, with some students reporting learning about interprofessional team function and roles through discussion with their CSLP partners, including discussions about their respective educational programs. One student partnership reported discussing their experiences of professional socialization.

\section{UNDERSTANDING OF HEALTH NEEDS AND RESOURCES}

Students described in-depth learning related to health needs and barriers to good health, as well as individual and community strengths and resources.

\section{Table 2.}

CBO clients' health needs. CBO clients' health needs that students described in their reflective assignments.

\begin{tabular}{|l|}
\hline Health needs: Support \\
\hline - Health services/resources \\
- Education \\
- Self-care \\
- Social support \\
- Basic needs: food \& shelter \\
\hline
\end{tabular}

Students reported their learnings related to clients' non-physical health needs in their reflective exercises, centred around the need for support (Table 2). One student wrote, "A friendly conversation and some nutritious food is often medicine enough for many clients."

In addition to learning about health needs, students learned, through experiences that were often described as "eyeopening" about underserved populations' deeply rooted and intertwined health issues. Most of the health barriers students observed converged around poverty and

social status. Students were asked to rank 12 health barriers included in the question: "Based on your CSLP experience, please rank the top three health/social issues that you feel are most important to the clients/communities served by your communitybased organization." Poverty was the health barrier students perceived to affect their CBOs' clients the most (Figure 1). Language barrier was not included in the original list, but was included frequently as another barrier.

Many students described arriving at a much deeper understanding of health barriers (Table 3): in their reflective assignments, many told stories of the difficulties of clients they saw, and the impact of the magnitude of these barriers on the students themselves. For example, one student told a story to describe the interrelated health barriers of poverty and lack of access to healthy food:

One of the women admitted that she and her kids never eat break-

Journal of Research in Interprofessional Practice and Education

Vol. 5.1

March 2015 fast. The [CBO worker] told her that even having one glass of milk in the morning is better than nothing. To this, the woman replied that she could not afford to buy a carton of milk. This statement shocked me... 
9

IP CSLP Evaluation

Clark, McKague, McKay, \& Ramsden
Figure 1.

Top-ranked health issues. Bar graph illustrates the percentage of students $(\boldsymbol{N}=32)$ who ranked each health/social issue in top three affecting their CBO's clients.

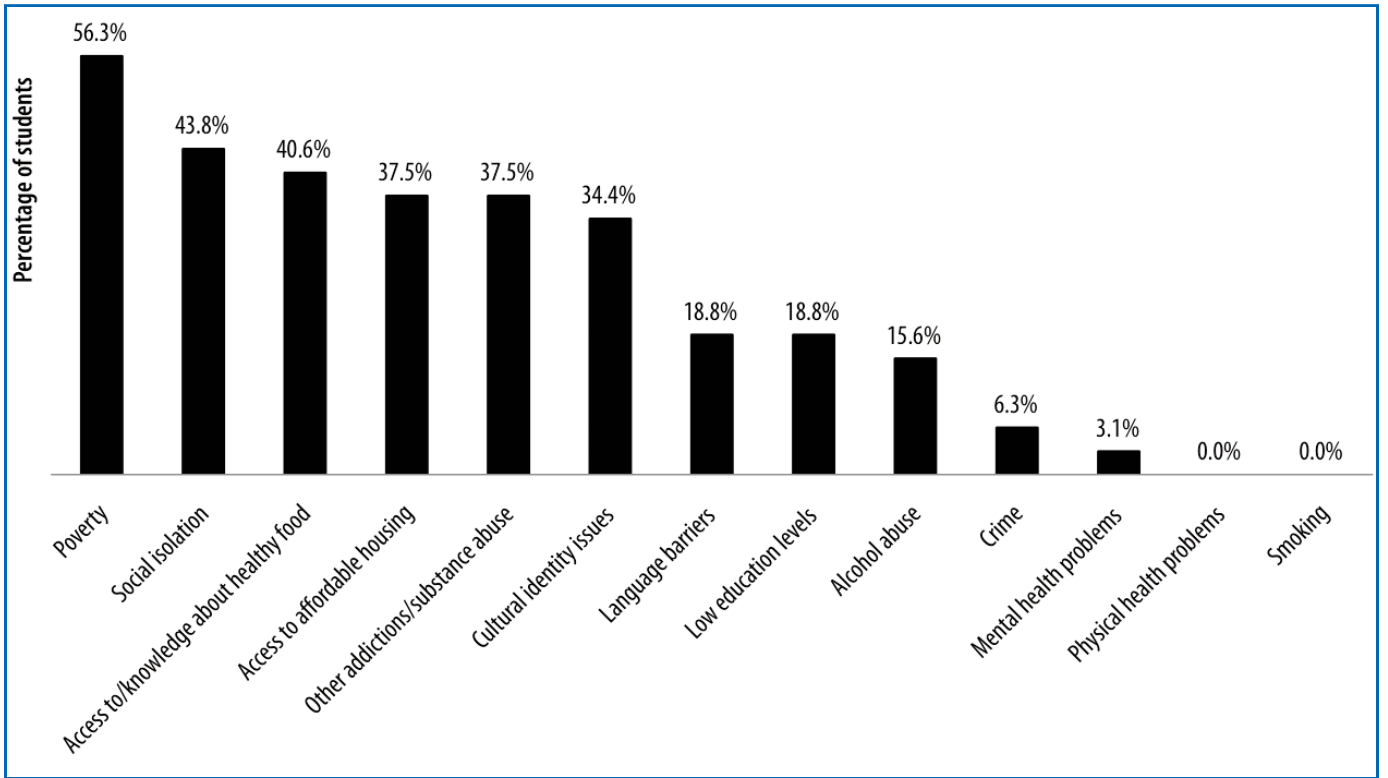

Table 3. Health barriers: Poverty and social status. CBO clients' health barriers that students described in their reflective assignments.

\begin{tabular}{|c|c|c|c|}
\hline $\begin{array}{l}\text { Barriers related to lack of } \\
\text { access }\end{array}$ & $\begin{array}{l}\text { Psychosocial health } \\
\text { barriers }\end{array}$ & $\begin{array}{l}\text { Health barriers } \\
\text { related to culture }\end{array}$ & $\begin{array}{l}\text { Systemic health } \\
\text { barriers }\end{array}$ \\
\hline $\begin{array}{l}\text { - Transportation access } \\
\text { - Low education levels } \\
\text { - Homelessness/housing issues } \\
\text { - Nutrition/lack of access to } \\
\text { healthy food/fast food and } \\
\text { convenience food diets } \\
\text { - Medication access } \\
\text { - Knowledge of healthcare } \\
\text { system } \\
\text { - Optometry/dentistry access } \\
\text { - Clothing access } \\
\text { - Hygiene maintenance }\end{array}$ & $\begin{array}{l}\text { - Social isolation/lack of } \\
\text { social support } \\
\text { - Lack of positive role } \\
\text { models } \\
\text { - Relationship issues } \\
\text { - Abuse } \\
\text { - Self-esteem issues } \\
\text { - Substance abuse/ } \\
\text { addictions } \\
\text { - General instability } \\
\text { - Mental illness } \\
\text { - Gangs and criminal } \\
\text { activity }\end{array}$ & $\begin{array}{l}\text { - Language barriers } \\
\text { - Culture shock }\end{array}$ & $\begin{array}{l}\text { - Systemic racism } \\
\text { - History of abuse } \\
\text { (residential schools) } \\
\text { - Mistrust of authority }\end{array}$ \\
\hline
\end{tabular}

While students had a deep experience of clients' health barriers and needs, they also encountered the strengths of clients and clients' communities (Table 4). Students described clients' strengths as unified by personal fortitude: motivation, endurance, hard work, and dedication. One student told a story of a newcomer client's daily schedule of waking up at 3:30 am to work at a grocery store, then taking the bus to 
JRIPE

10

IP CSLP Evaluation

Clark, McKague, McKay, \& Ramsden

attend language classes, then going home to care for his children while his wife worked the evening shift at a restaurant. Furthermore, students said that they learned about the strengths of clients' communities, centred around community members supporting each other, by observing and reflecting on communities' support networks and participation in $\mathrm{CBO}$ ' activities.

Table 4.

\section{Strengths of individuals and communities. Strengths of CBO clients and their communities that students described in their reflective assignments.}

\begin{tabular}{|l|l|}
\hline Strengths of individuals & Strengths of communities \\
\hline - Motivation & - Unity/mutual support \\
- Perseverance/hard work/dedication & - Culture \\
- Resilience/endurance & - Families \\
- Honesty/openness & - Participation and involvement in activities \\
- Willingness to learn/acceptance of assistance & - Self-regulation \\
- Positive attitudes & \\
- Intelligence & \\
- Resourcefulness & \\
- Considerateness: thankfulness, generosity, welcoming & \\
- Humility & \\
\hline
\end{tabular}

Students learned about the importance of addressing clients' health needs and barriers by working with clients' and communities' strengths as socially responsible healthcare professionals. All students surveyed $(N=32)$ agreed or strongly agreed that they had a professional responsibility to address health barriers. Students discussed in their reflective assignments the importance of healthcare professionals knowing community resources. $96.7 \%$ of students surveyed $(N=30)$ agreed or strongly agreed that their understanding of how $\mathrm{CBOs}$ address health and social issues improved due to the CSLP. In the survey, $16.7 \%$ disagreed or were unsure that they had increased knowledge of specific local services to address health/social issues $(N=30)$; however, the reflective assignment analysis showed that some students wanted to learn more about community resources outside their $\mathrm{CBO}$ placement.

Through increased understanding of clients' situations, students became more confident in their abilities to address the health issues of their underserved patients: $90.0 \%$ of students surveyed agreed or strongly agreed that they felt better prepared to deal with health/social issues as a result of the CSLP $(N=30)$. One student said, "I have learned the importance of offering support and treatment regimens that are realistic for patients to fulfill." Another student gave the example of providing patients with "more cost-effective options for medications and treatments."

Students also thought of ways that they as future healthcare professionals could reduce health barriers at a more systemic or professional policy level: students described the importance of increasing service accessibility, educating clients and professional peers, and expressed increased interest in practice in underserved areas. 
JRIPE

11

IP CSLP Evaluation

Clark, McKague, McKay, \& Ramsden

One pharmacy student wrote:

Before this experience, I always pictured myself working in a pharmacy in "the suburbs" of a city, where my patients would typically be middle class. Now I feel as if a possible option for me would be to work in a city's downtown core.

Students also stressed the importance of professional volunteerism, and many expressed their own volunteerism through a continued commitment to service at their CBO after the completion of the CSLP. Although only a few students reported directly observing political advocacy, many wrote about how they saw the broader implications of their experiences, extending their healthcare professional role to involve political advocacy in which communities participated and community needs were taken into account.

\section{CSLP process evaluation from students' perspective}

\section{CSLP ORGANIZATION}

Students reported that the CSLP was generally well-organized, and positively rated communication between themselves and the faculty coordinators, and agreed that program objectives $(M=4.27, S D=0.45, N=30)$ and coordinators' expectations $(M=4.22$, $S D=0.75 N=32$ ) were communicated clearly. This communication was achieved through e-mail, group sessions, handouts, mid-point evaluations, and reminders.

\section{REFLECTIVE PROCESS}

Most students $(M=4.06 / 5, S D=0.80, N=32)$ found the reflective sessions to be helpful, reporting them to be useful for thinking about and analyzing experiences, demonstrating learning, examining personal development, problem-solving, and sharing experiences. A few criticized reflective sessions as being repetitive, and a few suggested that sessions should include more discussion about the cycle of poverty and on other local community resources.

Different reflective assignment modalities evoked different responses. Individual final reflective assignments had an open format, with students being asked to discuss their "experience and key learnings." Reflections in these assignments were very introspective, as students explored their personal experiences, feelings, observations, and relationships. CSLP partners jointly completed other exercises at group sessions, and in response to structured questions gave specific examples of professional accountability, health barriers, observations, and ways to practice interprofessionally.

Journal of Research in Interprofessional Practice and Education

Vol. 5.1

March 2015

\section{CBO PLACEMENTS}

Within placements, the comments indicated that students were largely satisfied with their exposure to clients and CBOs'services. Some CBOs gave students exposure to local community services outside their $\mathrm{CBO}$ placement through discussion and referrals, but some students wanted more instruction on these services. 
JRIPE

12

IP CSLP Evaluation

Clark, McKague, McKay, \& Ramsden

A significant difference between students attending different $\mathrm{CBO}$ groups, $F(3,31)$ $=3.741, p=.022\left(M_{\text {group 2 }}=4.44, S D_{\text {group } 2}=0.527 ; M_{\text {group 1 }}=3.20, S D_{\text {group } 1}=0.919\right.$; $\left.M_{\text {group } 3}=4.00, S D_{\text {group } 3}=1.00 ; M_{\text {group } 4}=3.50, S D_{\text {group 4 }}=0.972\right)$ was found for the item on knowledge of contributions of members of other professions, likely indicating that students' learning in this area was dependent on what they were able to observe at their placements, a finding supported by qualitative analysis. At different $\mathrm{CBOs}$, students met different sets of professionals and other learners. The CBO placement found by both qualitative and quantitative analysis to have the best learning around specific interprofessional roles was an interprofessional student-run clinic. However, all CBOs seemed to teach students about interprofessional attitudes and teamwork skills through the $\mathrm{CBO}$ ' atmospheres of teamwork and equality.

\section{STUDENT PARTNERSHIPS}

Students' experiences of their CSLP student partnerships varied. $84.4 \%$ of students surveyed $(N=32)$ reported working with their medicine/pharmacy partners at their CBO placements at least some of the time, but only $15.6 \%$ "actively collaborated to plan activities and/or solve problems together" (Table 5). Some students reported gaining much from their partnership in terms of relationship-building, communication and teamwork skill-building. The most frequently named barrier to working with partners was scheduling difficulties: coordination was sometimes difficult due to students' busy schedules, despite program coordinators' efforts to partner students with similar schedules.

Table 5.

Collaboration between student partners. This table shows the frequency of how students rated collaboration with their CSLP partners

Journal of Research in Interprofessional Practice and Education

Vol. 5.1

March 2015

\begin{tabular}{|l|l|}
\hline Response $(\boldsymbol{N}=\mathbf{3 2})$ & \% Frequency \\
\hline Only worked together during orientation/reflective sessions (=3) & 15.6 \\
Worked at our placement at least some of the time, but did not plan & 43.8 \\
activities or solve problems together $(=4)$ & $\begin{array}{l}\text { 84.4\% of students } \\
\text { worked together } \\
\text { at their CBO place- } \\
\text { ment at least } \\
\text { some of the time }\end{array}$ \\
\hline Actively collaborated to plan activities and/or solve problems together $(=6)$ & 15.6 \\
\hline Total & $\mathbf{1 0 0 . 0}$ \\
\hline Mean $=\mathbf{4 . 4 1 / 6}$ & Standard Deviation $=\mathbf{0 . 9 4 6}$ \\
\hline
\end{tabular}

Some students acknowledged that because their $\mathrm{CBO}$ offered volunteering opportunities that could be arranged on short notice, they put minimal effort into scheduling volunteering times with their CSLP partners. ANOVA testing found significant differences between $\mathrm{CBO}$ in partner collaboration ratings, likely for this reason, $\mathrm{F}(31)=3.131, p=.041\left(M_{\text {group } 1}=4.8 ; M_{\text {group } 2}=3.89 ; M_{\text {group } 3}=5.33 ; M_{\text {group } 4}=4.20\right)$; qualitative analysis showed that the CBOs offered different types of activities, requiring differing amounts of student collaboration. Some students suggested more 
IP CSLP Evaluation

Clark, McKague, McKay, \& Ramsden mandatory meetings between partners to improve collaboration. A few said that they preferred to work alone because of increased opportunity for client contact due to greater client comfort with one-on-one interactions.

Students mentioned factors that improved collaboration with partners: program factors of compatible schedules and emphasis from coordinators on teamwork, and personal factors of partners having similar expectations; communication, a desire to learn from partners, and commonalities to form a relationship upon.

\section{Unexpected outcomes: Personal and emotional development}

As well as outlining their development of client-centred attitudes and skills for future practice, students also described their personal development in many areas. Many students discussed how they grew socially through the relationships they built with CSLP partners, $\mathrm{CBO}$ clients, $\mathrm{CBO}$ coordinators, other $\mathrm{CBO}$ volunteers and professionals, and other CSLP students. A few students even related their ethical and spiritual growth.

Students recounted the processes of their emotional development throughout the CSLP (Figure 2). This flowchart illustrates themes in students' feelings throughout

Figure 2.

\section{Students' emotional development. Flowchart illustrates students' feelings throughout the project as described in reflective assignments and comments.}

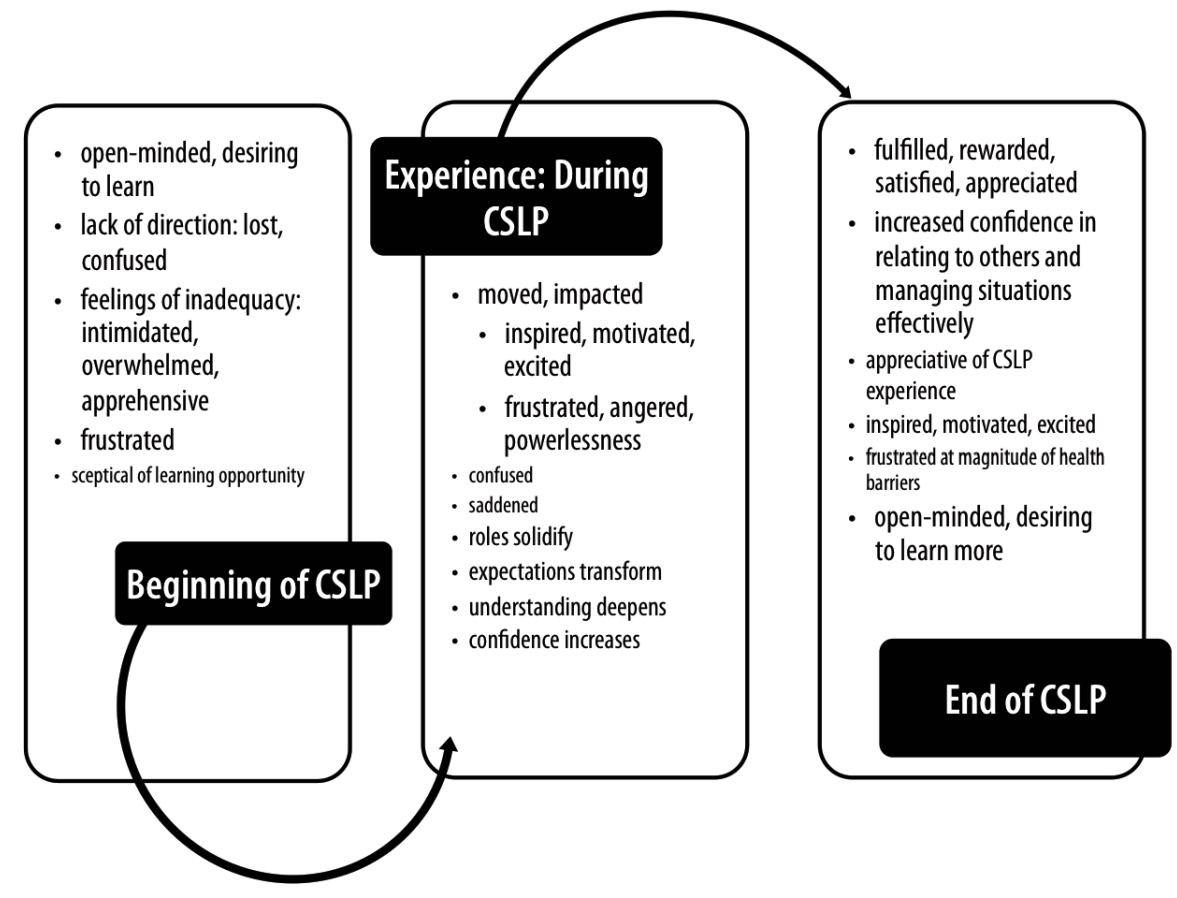

Note: Font size indicates the strength of the themes.

the project that we found in their reflective assignments and questionnaire comments. Many came into the project with positive attitudes (like open-mindedness and an openness to learning), but some also felt scepticism regarding the usefulness of the experience, frustration, a sense of being lost and confused due to a lack of 
IP CSLP Evaluation

Clark, McKague, McKay, \& Ramsden
Journal of Research in Interprofessional Practice and Education

Vol. 5.1

March 2015

\section{Journal of Research in Interprofessional Practice and Education}

direction or lack of clarity in their roles at CBOs (for one student, volunteering "began in a state of disarray"), or experienced feelings of inadequacy like feeling apprehensive, intimidated, or overwhelmed. One student disclosed:

Some of the situations clients at the [CBO] face ... seemed overwhelming and I felt like I might be inadequate and unable to be that helpful to the clients. It seemed like I would know nothing about the situations clients face and I have never felt more like a naive person from a small town.

Students' experiences over the course of the project caused their expectations to transform, and included a host of enmeshed emotions as they were impacted by what they encountered: from confusion to sadness to inspiration and excitement to anger and frustration.

Students' skills and their confidence in those skills' effectiveness also increased over the course of their experiences to a point where, by the end of the CSLP, they reported increased confidence in managing situations successfully and in relating to clients and staff. After describing the challenge of discussing a difficult topic with $\mathrm{CBO}$ clients, one student said, "If I went through the situation again, I would definitely feel more prepared to deal with it." Of course, the complexity of human emotion is such that some students also mentioned leaving the project with a feeling of frustration at the magnitude of the health barriers that underserved populations face, a feeling one student described:

This was frustrating for me to see as well because it seems on numerous occasions, just when it seems that one of the community members is on the way to improving their situation by finally finding a job or a stable place to live, or quitting drugs and drinking, something happens so that they fall right back to where they used to be.

Those feelings, however, seemed to be overshadowed by students feeling fulfilled and rewarded, appreciative of the experience, and inspired and excited. One student wrote, "All in all, this learning experience has been invaluable." Another called the experience "much more fulfilling than I could have imagined." Students were generally very happy with their CSLP experience: $96.7 \%$ of students surveyed agreed or strongly agreed that they were satisfied with the experience overall $(N=30)$.

\section{Students' learning processes}

Another somewhat unexpected finding was how students learned (Figure 3). This flowchart summarizes our findings from reflective assignments on students' experiential learning process. The qualitative analysis revealed the following learning processes: students' activities at CBOs gave rise to their experiences; students' experiences consisted of their observations, feelings, and relationship-building. Through reflection, students drew learning from their experiences: developing both professionally and personally, learning about the client-centred approach, interprofession- 


\section{JRIPE}

15

IP CSLP Evaluation

Clark, McKague, McKay, \& Ramsden alism and themselves. The role of the relational and affective components of the learning process was bigger than we expected.

Figure 3.

\section{Students' experiential learning process. Flowchart illustrates students' experiential learning process, determined through qualitative analysis.}

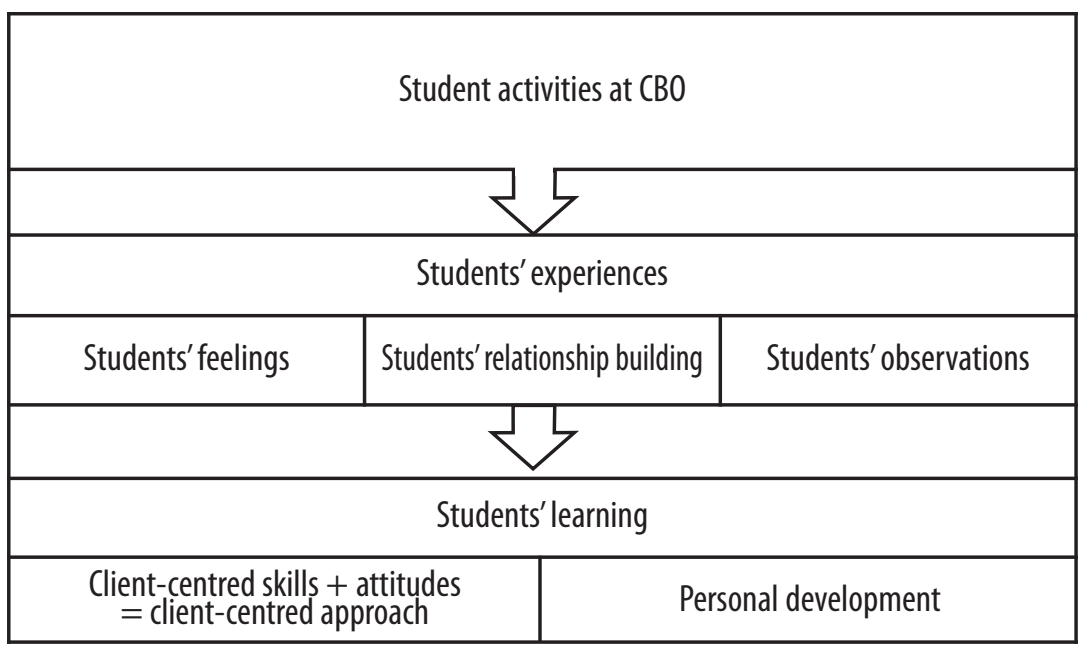

\section{CBO coordinator interviews}

\section{Outcomes evaluation}

\section{PERCEIVED OUTCOMES FOR STUDENTS}

\section{CLIENT-CENTRED APPROACH}

One $\mathrm{CBO}$ coordinator commented on students' learning through interacting with the clients: "[students] actually do interact with the clients and learn things about them, consistently, to realize the different social determinants [of health]." She went on to say, "[a]nd [students] find that, they discover that on their own." All three coordinators reported that they saw students learn about the social determinants of health, especially $\mathrm{CBO}$ clients' health barriers, which one coordinator described extensively. One coordinator said she observed students develop client-centred attitudes, naming open-mindedness and patience. Another coordinator said that students' stereotypes of clients were challenged. All three coordinators mentioned improved communication skills with $\mathrm{CBO}$ clients (for one $\mathrm{CBO}$, through language barriers) as a client-centred skill that students gained.

Another coordinator reported students observing $\mathrm{CBO}$ workers' client-centred skills at the $\mathrm{CBO}$, such as $\mathrm{CBO}$ workers providing immediate counselling to clients in crisis, dealing with conflict between clients, and helping clients while maintaining emotional distance from clients' issues.

\section{INTERPROFESSIONAL EDUCATION}

All three $\mathrm{CBO}$ coordinators reported observing relationship-building, communication and support occurring within the student partnerships. Only one coordinator com- 
IP CSLP Evaluation

Clark, McKague, McKay, \& Ramsden

Journal of Research in Interprofessional Practice and Education

Vol. 5.1

March 2015

\section{Journal of Research in Interprofessional Practice and Education}

mented that she observed students developing positive attitudes towards interprofessionalism, such as seeing its benefits, with the time they spent at the CBO. This coordinator's CBO's structure involved the most exposure to an interprofessional team.

\section{PERSONAL DEVELOPMENT}

All three of the coordinators conveyed that they observed students' personal development as students progressed in their CSLP. The coordinators commented on students' confidence growing as their comfort level and skills, such as leadership skills or program direction skills, at the CBO increased. One coordinator said, "I think I've seen, in many cases, students just mature: I just see them mature as people because they have a deeper perspective." Another coordinator described this "perspective": "[students] learned about everything we take for granted. You know, as, as middleclass people."

An unexpected theme regarding students' empathy arose when a CBO coordinator commented on a perception of students being emotionally more distanced from the clients' problems, which led to questioning of the CSLP's long-term effects:

I think [students] felt it [the gravity of clients' social issues], but ... [the students] have a lot of youth, and they don't show their emotions as much as, as much as the staff. Yeah. I think, too, I think, too, that they know that at the end of their term with us, they go back to their own life.

This same $\mathrm{CBO}$ coordinator expressed thoughts that students needed even more exposure to $\mathrm{CBO}$ clients and $\mathrm{CBO}$ work, saying, "some of this stuff you don't learn until, unless you've been in it for a few years."

\section{REPORTED OUTCOMES FOR CBOS}

Coordinators reported that the CSLP resulted in an increased workload, more than for general $\mathrm{CBO}$ volunteers, in scheduling and coordinating on their parts, but that this was balanced by benefits to CBOs and clients. One coordinator said, "yes, there was more coordinating and planning on our part, but the greater benefit was for the clients, so it was more than worthwhile." Two of the coordinators said that the extra contact they had with students resulted in an increased relationship with the students.

A prominent reported benefit to all three of the CBOs was volunteer staffing. One coordinator said, "Sixty hours is a lot, so they really do add so much to those programs from September to April, that when they leave, we really notice the difference." Another coordinator mentioned that students' help decreased the CBO workers' workload, so that $\mathrm{CBO}$ workers could spend more time on direct client care. Two coordinators mentioned CSLP students continuing to volunteer at the CBO after the completion of the CSLP, and one coordinator mentioned CSLP students becoming leaders within the CBO: "I think [CSLP students] do become really good ambassadors for [CBO name]."

Two coordinators also said that they found the CSLP to provide the CBO with a beneficial opportunity to make connections to the university and community. One 


\section{Journal of Research in Interprofessional Practice and Education}

articulated: "[The CSLP] gives you a chance to work, work with the community, work with the university ... it creates an awareness. It lets the city know that we're here."

A difference in how the students affected the CBOs was in how the coordinators perceived the CSLP students as compared to other CBO volunteers. One coordinator expressed, "We do get quite a few university students, but the pharmacy and medicine students seem to be more mature and just more capable. So we really like having them because the quality of work is so good." On the other hand, another coordinator stated, "I don't really know that there's that much difference between [CSLP students] and the other [volunteers] except for the amount of time that they're obligated to spend here." This coordinator did, however, report finding the quality of CSLP students' work to be very good, saying, "I found all of them to be really engaged."

One coordinator named an unexpected benefit for $\mathrm{CBO}$ s, that clients "behave better" when new people are present. Another unexpected benefit for CBOs surfaced when one coordinator discussed extensively how she had students who were comfortable submitting their final reflective assignments to her, and then how she found this to be a useful tool for her own assessment of the $\mathrm{CBO}$ achieving its goals in educating volunteers:

The reflective papers are great, because I really do get it, it allows me to see if [students] are really gaining insight to what that sort of interprofessional advantage is, and the social determinants [of health]. And they're all in there, so I know that they're getting [it], I can use that as a tool, you know, from my end, to see, to assess whether they're actually getting what they should be getting out of being here at [CBO name].

\section{PeRCEIVED BenefiTS TO CBO CLIENTS}

Coordinators mentioned various benefits that students provided clients, centred around support. One coordinator said, "[the students' presence] showed [clients] that, that society cares about them. Yeah, you know, that they're special enough that the university can send these students to work with them." One coordinator discussed the mentorship and support that students provided immigrant and refugee clients in a one-on-one or two-on-two mentorship program, saying, "[students would] just be a support system here in Canada, become [a client's] friend, and, you know, whatever guidance [students] could offer." She went on to say, "it's basically one of [a client's] best Canadian friendships they've made, ... through meeting the students at the university."

Two of the coordinators discussed the importance of students' consistency as a predominant factor in increasing clients' comfort and trust in students and the CBO. One coordinator articulated that she thought the clients who had the most one-on-one contact with the students gained the most benefit from them. CBO coordinators saw the important part that students building relationships with clients played in the CSLP. 


\section{Journal of Research in Interprofessional Practice and Education}

\section{Process evaluation}

$\mathrm{CBO}$ coordinators interviewed reported their satisfaction with the CSLP's overall organization.

In terms of other program factors pertaining to students' time at CBOs, both of these coordinators discussed the benefits, both for students and clients, of students volunteering consistently both at one program and with their CSLP partner. Both saw some student partnerships work together more than others. Two coordinators discussed that they saw differences between partnerships who worked together frequently and those who did not. One coordinator described partnerships who did not work together frequently as "more of almost strangers coming together when they had to."

One coordinator discussed the benefit of a greater number of service hours on student learning: "If they didn't spend sixty hours here, [students] wouldn't get it [clients' situations] quite as extensively as they do. So I think the number of hours makes a huge difference, because they're really engaged." One coordinator mentioned the importance of letting students choose their own service placement as a factor in a CSL project's success: "I was just at [another university CSL program] meeting, and ... they found [the CSL program] much more successful when the students could pick where they want to go, because that's kind of a self-motivation, motivator."

\section{REFLECTIVE SESSIONS}

Two of the CBO coordinators interviewed reported experiencing difficulty attending all of the meetings and reflective sessions, but had different feelings about missing them. Both said that their responsibilities in face of program direction and time constraints at their CBOs outweighed the perceived benefits of attending a reflective session at least once. One coordinator expressed regret and a sense of lack of closure and missed opportunity from missing the final reflective session, while the other coordinator said she felt her presence at reflective sessions might discourage students from being totally honest about their experiences with her CBO.

\section{DIFFERENCES BETWEEN CBOS IN TERMS OF RELATIONSHIP LENGTH WITH CSLP}

The third $\mathrm{CBO}$ coordinator we interviewed had far fewer in-depth comments regarding the CSLP's processes. While the other two CBOs had been part of the CSLP for several years, the third coordinator's CBO had just finished a first year participation in the CSLP, and the coordinator had only taken on the CBO coordinator responsibilities partway through the year.

He also described how, over the course of the year, the CBO grew in an understanding of students' roles: "One of the things I didn't realize at the beginning myself, was that the students needed to be allowed to work independently, or more independently." He reported the following:

So myself and the [other non-CSLP CBO] volunteers, we didn't realize that was supposed to be happening, and so we were over-, overstepping. Like, we were, you know, when somebody would come up to the front counter and ask for something, instead of letting the stu- 


\section{JRIPE}

19

IP CSLP Evaluation

Clark, McKague, McKay, \& Ramsden

Journal of Research in Interprofessional Practice and Education

Vol. 5.1

March 2015

\section{Journal of Research in Interprofessional Practice and Education}

dent answer, one of us would answer, okay? So we didn't realize that, that that needed to happen. But now, but now, I was more aware of it in the springtime, so more of that happened, and students were able to grow. Grow quickly.

\section{CBO client interviews}

\section{Perceived outcomes for students}

\section{CLIENT-CENTRED APPROACH}

All three clients identified sharing knowledge of their cultures as being important to student learning. One client discussed teaching interested students about Aboriginal beadwork at a programming group at a $\mathrm{CBO}$. The other two clients, who were both newcomers to Canada, reported sharing information about their home countries and cultures with the CSLP students with whom they were paired.

Two of the clients described students' learning about the client-centred and holistic approaches to health. One client excellently outlined the client-centred attitudes of open-mindedness and adaptability when she said that she thought students who volunteered at her $\mathrm{CBO}$ "[learned] not to be so narrow-minded, that there's so many different people out there. Like, so many people that need different things. And not to treat everybody all one way." This same client also demonstrated what she could teach students about the importance of client choice by saying, "Because you can only help [other people] so far. It's just that they have to go the other half and do it for themselves. Because if they don't want to do it, then they're not going to."

\section{PERSONAL DEVELOPMENT}

One client noticed students' increased comfort and confidence with the time they spent at the CBO. She said, "Because I know a couple, you can tell when they're new, because they're really shy, and they don't know what to say. And, yeah, but then you slowly see them come out of it."

\section{Reported outcomes for clients}

\section{RELATIONSHIPS}

All three clients discussed the relationships they built with CSLP students and/or CBOs. The two clients who worked one-on-one with CSLP students both mentioned their friendships with those students. Both clients who built strong relationships with particular CSLP students commented on learning about the students and on the students learning about them. One client discussed how she felt working with her helped students learn in a much more experiential way, and that this was beneficial for students because "you finally start to see it. Like, you don't actually just see it in the book, like, hear it in a book."

\section{CBO SERVICES}

All three clients reported having positive and beneficial experiences at the CBOs, and one client said she would prefer to work with a CSLP student over a general 
IP CSLP Evaluation

Clark, McKague, McKay, \& Ramsden

$\mathrm{CBO}$ volunteer. Two clients emphasized that students volunteering at the CBOs provided a benefit to many clients. One client described some personal benefits she received from the CBO: she mentioned her increased comfort and increased confidence, which she attributed to spending time at the $\mathrm{CBO}$, saying, "[being at the $\mathrm{CBO}$ help me quit being shy." One client described the support the CBO provided her while she was working through a health problem: "It really helped talking to [CBO student volunteers and CBO workers]." All three clients discussed benefiting personally from the CBOs.

\section{LANGUAGE SKILLS}

Two of the clients, who were both newcomers to Canada, discussed how much spending time with their CSLP students directly provided them benefit in the area of their language skills. One client said, "before [CSLP student's name], I couldn't speak English. But when I met with [CSLP student's name], yeah, I can speak English.” Her husband elaborated, "You should have met my wife before [CSLP student's name]," and continued on to say how much the scope of the activities she could do in Canada increased: "Now, she can go [on the] computer or shopping." Her husband made a comment on the importance of experiential learning for gaining language skills: "Through studying at school, you can't get good strength in speaking."

\section{CSLP processes}

Despite all of their in-depth commentary about the CSLP's outcomes for both students and themselves, the CBO clients who were interviewed had very few comments about the CSLP processes.

\section{Discussion}

\section{Limitations and future research}

Each service-learning program is structured differently. Our results may be dependent on learning settings, which may limit the generalizability of our findings.

This CSLP's intake process allowed students to choose to participate, and appeared to have attracted at least some students with prior interest in working with underserved populations. It is difficult to know whether the findings regarding student learning and personal development would also apply to a group of students without a pre-existing orientation towards working with newcomer and underserved urban clients.

We studied students' learnings at the completion of the CSLP, but we did not follow up with students years after completing the program to assess any long-term impacts on career choices or client-centred approach.

Journal of Research in Interprofessional Practice and Education

Vol. 5.1

March 2015

\section{Interprofessional education}

Similar to other studies on interprofessional education in students' early years $[17,18]$, we found that key outcomes were in two areas: attitudes towards/interest in interprofessionalism and teamwork skills, namely relationship-building and communication skills. This was a prominent theme in students' comments, reflective assignments, 
and quantitative survey results. This was also supported by one CBO coordinator's interview.

Consistently, we found increased knowledge of interprofessional teamwork and roles to be a less prominent theme, despite students reportedly meeting a wide variety of professionals. This may be, in part, because students' professional identities and roles are not highly developed early on in their education.

What was learned did vary from $\mathrm{CBO}$ to $\mathrm{CBO}$. Our qualitative analysis of questionnaire comments and reflective assignments also showed that $\mathrm{CBOs}$ varied in exposure to other healthcare professionals and non-healthcare professionals, based on $\mathrm{CBOs}$ ' own internal structure.

The $\mathrm{CBO}$ with the best scores for the interprofessional knowledge questionnaire item is a student-run clinic where mentors and senior students from different healthcare professions participate in clearly defined roles specific to their profession. To account for students' increased interprofessional knowledge, we attribute the unique structure of this student-run clinic and its coordinator's conscious support of interprofessional education. If knowledge of interprofessional roles remains a goal of this type of early interprofessional experience, we may need to intentionally seek out $\mathrm{CBO}$ partners where interprofessionalism is a mandate of the organization.

The partnerships' perceived usefulness to students and students' desires to work with their interprofessional partners varied. Similarly, $\mathrm{CBO}$ coordinators found differences between student partnerships in terms of how closely they worked together. $\mathrm{CBO}$ coordinators also found teamwork skills developing through the relationships of partnerships who worked together more closely. The helpfulness of relationship and teamwork skill-building through the partnerships was a prominent theme in students' comments. Matching students to each other's schedules and to CBOs that can support these schedules may be one important factor in fostering this teamwork skill building.

We maintain that interprofessional educational opportunities are important for students in the early years of their education, as attitudes and interests built by these experiences set a foundation for future interprofessional work.

\section{Client-centred approach}

Consistent with community service-learning literature $[4,6,10,12,20]$, we found the CSLP fostered client-centred attitudes and skills, including communication skills, understanding of health barriers and needs, attitude change, and understanding of the need for community service. This finding was consistent between all three participant groups.

\section{PERSONAL DEVELOPMENT}

In accordance with other service-learning literature [19, 23], clients, CBO coordinators and students alike described students developing confidence, empathy, maturity and a sense of social accountability over the course of the CSLP. Students, CBOs and clients described a mutual benefit from participating in the CSLP. 
IP CSLP Evaluation

Clark, McKague, McKay, \& Ramsden

Journal of Research in Interprofessional Practice and Education

Vol. 5.1

March 2015
Journal of Research in Interprofessional Practice and Education

\section{Learning process}

\section{Reflective modalities}

Consistent with previous literature $[4,6,10,19]$, we agree that reflection, both written and oral, individual and group, is a key mechanism of service-learning. We found Barner's comment [4] that reflective assignments capture the depth of students' learning and development to be especially true for reflective assignments with an open format. Our findings suggest that reflection can be difficult to participate in because it can be time-consuming for both students and busy CBO coordinators. Our findings also suggest that some students and $\mathrm{CBO}$ coordinators may not value the exercise of reflecting as much as we do.

\section{Relationship building}

We found that students learned through experience, which we saw as divided into three components: observations, feelings, and relationships. Relational and affective components of the learning process were more prominent than we expected, from all three participant groups. Through relationships, learning was reciprocal between clients and students: both acted as teachers. Other researchers $[20,23]$ supported our findings that students' relationship-building with community members and $\mathrm{CBO}$ workers was a crucial means for achieving a depth of understanding and attitude change.

Interestingly, some students found their CSLP partnerships to be restrictive to building good one-on-one relationships with clients, through which both the clients and students could learn. We infer that these students valued their learning from relationships with clients more than their learning from relationships with CSLP partners. The project is structured so that some one-on-one activities with clients are more easily carried out by students individually than while working with their CSLP partners.

\section{Emotional involvement}

Our findings are consistent with others': Kiely [19] and Rhoads [20] described students' emotional involvement in service-learning experiences as being integral to their learning, which Kiely called the "affective dimension" as opposed to the "cognitive dimension" of learning [19]. Many students described emotional involvement as being important to their learning.

One $\mathrm{CBO}$ coordinator made a discordant comment about students maintaining emotional detachment, remaining separated from the CBO clients, and perceived that students needed to spend more time at $\mathrm{CBOs}$ before really learning empathy. This phenomenon was also reported in another study on a service-learning project, in which one community member stated, "when you go home, if there is no relationship after that, then you really are still living in two different worlds" [22]. We note that this was not reported by our other $\mathrm{CBO}$ supervisors. We do not know what led to this comment, but this was the $\mathrm{CBO}$ newest to the project. This $\mathrm{CBO}$ had not yet had students returning year after year, and students made up a smaller part of its volunteer base. 


\section{JRIPE}

23

IP CSLP Evaluation

Clark, McKague, McKay, \& Ramsden

We postulate that over time, $\mathrm{CBO}$ coordinators see students, as a collective, growing personally from the CBO's involvement. It does take time and repeated efforts, however, to continue to work at decreasing (never totally eliminating) the barrier between students and underserved populations. The changes we studied in our CSLP were significant, but our study and the students' immersion experiences were admittedly short-term.

\section{Experiential and transformative learning}

The newest $\mathrm{CBO}$ coordinator made a comment that students needed to be given independence to really learn, and students likewise described learning more as they gained independence.

Some service-learning literature involving deeply immersive or longitudinal experiences describes service-learning as a transformative process for students $[19,23]$. Given that some other service-learning programs that involved similar experiences did show that the programs influenced career choice $[19,21,22]$, we hope that this program may have similar impacts. While we similarly found changes in students' perceptions of societal structures and sometimes planned career trajectories, we did not evaluate the long-term changes in students' behaviour to be able to tell if a lasting transformation actually occurred.

\section{Relationships with CBOs}

The newest $\mathrm{CBO}$ coordinator also gave the fewest comments on the CSLP's processes. The differences we observed between the third coordinator's comments on processes and the comments of the first two coordinators demonstrated to us something well-known throughout service-learning literature: how relationships between universities and CBOs are built over time, through trial and error and through extensive communication.

\section{Conclusions}

The community service-learning experiences impacted students. It gave them a first interprofessional exposure and positively affected their attitudes towards interprofessionalism. It also gave them some insight and skills that they can use to work more effectively with clients in urban, underserved communities.

\section{Acknowledgements}

We would like to thank:

- $\mathrm{CBO}$ partners who provide students with unparalleled learning opportunities.

Journal of Research in Interprofessional Practice and Education

Vol. 5.1

March 2015
- The students, CBO clients, and CBO coordinators who have enthusiastically taken part in the CSLP and its evaluation.

- Bev Allen (1951-2013) of the College of Pharmacy, who was instrumental in establishing the CSLP and worked committedly as CSLP Co-Coordinator from 2005-2011. 
24

IP CSLP Evaluation

Clark, McKague, McKay, \& Ramsden

\section{Abbreviations}

CBO: community-based organization

CSLP: Community Service-Learning Project

\section{Note}

1. We use the term client-centred care, as the organizations involved in this program commonly use the term "clients" rather than "patients."

\section{References}

1. Bolen, C., \& Heck, J. (1995). Defining and measuring the social accountability of medical schools. URL: http://whqlibdoc.who.int/hq/1995/WHO_HRH_95.7.pdf [August 7, 2011].

2. Global Consensus for Social Accountability of Medical Schools. (2010). Consensus Document. URL: http://healthsocialaccountability.sites.olt.ubc.ca/files/2011/06/11-06-07-GCSA-English-pdfstyle.pdf [August 7, 2011].

3. Association of Faculties of Medicine of Canada. (2009). The future of medical education in Canada: A collective vision for MD education. URL: http://www.afmc.ca/future-of-medical-education-incanada/medical-doctor-project/index.php [August 7,2011].

4. Barner, J.C. (2000). First-year Pharmacy students' perceptions of their service-learning experience. American Journal of Pharmaceutical Education, 64, 266-271.

5. Acosta-Deprez, V., \& Sinay, T. (2009). Reaffirming the role of service learning in public health curricula. In Pelham, A., \& Sills, E. (Eds.), Promoting health and wellness in underserved communities: Multidisciplinary approaches through service learning. (pp. 3-18). Sterling, VA: Stylus.

6. Seifer, S.D. (1998). Service-learning: Community-campus partnerships for health professions education. Academic Medicine, 73, 273-277.

7. Bolen, C. (2000). Towards unity for health: Challenges and opportunities for partnership in health development: A working paper. URL: http://www.who.int/hrh/documents/en/TUFH _challenges.pdf [August 7, 2011].

8. Health Canada. (2001). Social accountability: A vision for Canadian medical schools. URL: http://www.hc-sc.gc.ca/hcs-sss/alt_formats/hpb-dgps/pdf/pubs/2001-social-vision-med/2001social-vision-med-eng.pdf [August 7, 2011].

9. Centre for the Advancement of Interprofessional Education. (2002). Defining IPE. URL: http://www.caipe.org.uk/about-us/defining-ipe/ [June 2, 2011].

10. Reynolds, P.J. (2009). Connecting interprofessional education to the community through service learning and community-based research. In Royeen, C.B., Jensen, G.M., \& Harvan, R.A. (Eds.), Leadership in interprofessional health education and practice. (pp. 167-187). Sudbury, MA: Jones and Bartlett.

11. Barr, H., Koppel, I., Reeves, S., Hammick, M., \& Freeth, D. (2005). Effective interprofessional education: Argument, assumption and evidence. Oxford, UK: Blackwell.

12. Elam, C.L., Sauer, M.J., Stratton, T.D., Skelton, J., Crocker, D., \& Musick, D.W. (2003). Service learning in the medical curriculum: Developing and evaluating an elective experience. Teaching and Learning in Medicine, 15(3), 194-203.

13. Long, A., Larsen, P., Hussey, L., \& Travis, S. (2001). Organizing, managing and evaluating servicelearning projects. Educational Gerontology, 27, 3-21.

14. Proctor, P., Lake, D., Jewell, L., Racine, L., D’Eon, M., \& Reeder, B. (2010). Influencing student beliefs about poverty and health through interprofessional community-based educational experiences. Journal of Research in Interprofessional Practice and Education, 1, 145-158.

15. Creswell, J.W., \& Plano Clark, V.L. (2011). Designing and conducting mixed methods research, $2^{\text {nd }}$ edition. Thousand Oaks, CA: Sage Publications.

16. Crabtree, B., \& Miller, W. (1999). Doing qualitative research, $2^{\text {nd }}$ edition. Thousand Oaks, CA: Sage Publications.

17. Cooper, H., Spencer-Dawe, E., \& McLean, E. (2005). Beginning the process of teamwork: Design, implementation and evaluation of an interprofessional education intervention for first year undergraduate students. Journal of Interprofessional Care, 19(5), 492-508.

Journal of Research in Interprofessional Practice and Education

18. Hoffman, S.J., \& Harnish, D. (2007). The merit of mandatory interprofessional education for prehealth professional students. Medical Teacher, 29(8), e235-e242.

19. Kiely, R. (2005). A transformative learning model for service-learning: A longitudinal case study. Michigan Journal of Community Service Learning, 12(1), 5-22.

20. Rhoads, R.A. (1997). Community service and higher learning: Explorations of the caring self. Albany: State University of New York Press.

March 2015 


\section{JRIPE}

25

IP CSLP Evaluation

Clark, McKague, McKay, \& Ramsden

\section{Journal of Research in Interprofessional Practice and Education}

21. Artz, L. (2001). Critical ethnography for communication studies: Dialogue and social justice in service-learning. The Southern Communication Journal, 66(3), 239-247.

22. Jones, S.R., \& Hill, K. (2001). Crossing High Street: Understanding diversity through community service-learning. Journal of College Student Development, 42(3), 204-216.

23. Pompa, L. (2002). Service-learning as crucible: Reflections on immersion, context, power, and transformation. Michigan Journal of Community Service Learning, 9(1), 67-76. 